\title{
Put your weight behind it - effect of BMI on the active second stage of labour: A retrospective cohort study.
}

\author{
Tilde Østborg ${ }^{1}$, Ragnar Sande ${ }^{1}$, Joerg Kessler ${ }^{2}$, Christian Tappert ${ }^{3}$, Philip Brandis ${ }^{1}$, and \\ TM Eggebo ${ }^{3}$ \\ ${ }^{1}$ Stavanger University Hospital \\ ${ }^{2}$ Haukeland University Hospital \\ ${ }^{3}$ Trondheim University Hospital (St. Olavs Hospital)
}

January 18, 2022

\begin{abstract}
Objective: To explore the duration of the active phase of the second stage of labour in relation to maternal prepregnant body mass index (BMI). Design: Retrospective cohort study. Setting: Labour wards of three Norwegian university hospitals, 20122019. Population: Nulliparous and parous women without previous caesarean section with a live singleton foetus in cephalic presentation and spontaneous onset of labour, corresponding to the Ten Group Classification System (TGCS) group 1 and 3. Methods: Women were stratified to BMI groups according to WHO classification, and estimated median duration of the active phase of the second stage of labour was calculated using Kaplan-Meier analyses. We performed stratified analyses in women with and without epidural analgesia and oxytocin augmentation. Finally, we calculated the Hazard Ratio (HR) of delivery using Cox regression analyses. Caesarean sections and operative vaginal deliveries during the active phase were censored. Main Outcome Measures: Estimated median duration of the active phase of second stage of labour. Results: The final study population comprised 23516 women in TGCS group 1 and 27255 in group 3. Increasing BMI was associated with shorter estimated median duration of the active phase in both TGCS groups. The pattern remained when performing stratified analyses for epidural and oxytocin analgesia. The HR for delivery increased significantly with increasing BMI analysed as a continuous variable; HR 1,019 (95\% CI 1.016-1.023) in TGCS group 1 and HR 1,017 (95\%CI 1.014-1.020) in TGCS group 3. Conclusion: Increasing BMI was associated with shorter estimated median duration of the active second stage Funding: None.
\end{abstract}

\section{Hosted file}

220114_MANUSCRIPT_BJOG.docx available at https://authorea.com/users/456004/articles/553204put-your-weight-behind-it-effect-of-bmi-on-the-active-second-stage-of-labour-aretrospective-cohort-study

\section{Hosted file}

211117_Table_1.docx available at https://authorea.com/users/456004/articles/553204-put-yourweight-behind-it-effect-of-bmi-on-the-active-second-stage-of-labour-a-retrospectivecohort-study

\section{Hosted file}

211117_Table_2.docx available at https://authorea.com/users/456004/articles/553204-put-yourweight-behind-it-effect-of-bmi-on-the-active-second-stage-of-labour-a-retrospectivecohort-study

\section{Hosted file}


210114_Table_S1.docx available at https://authorea.com/users/456004/articles/553204-put-yourweight-behind-it-effect-of-bmi-on-the-active-second-stage-of-labour-a-retrospectivecohort-study
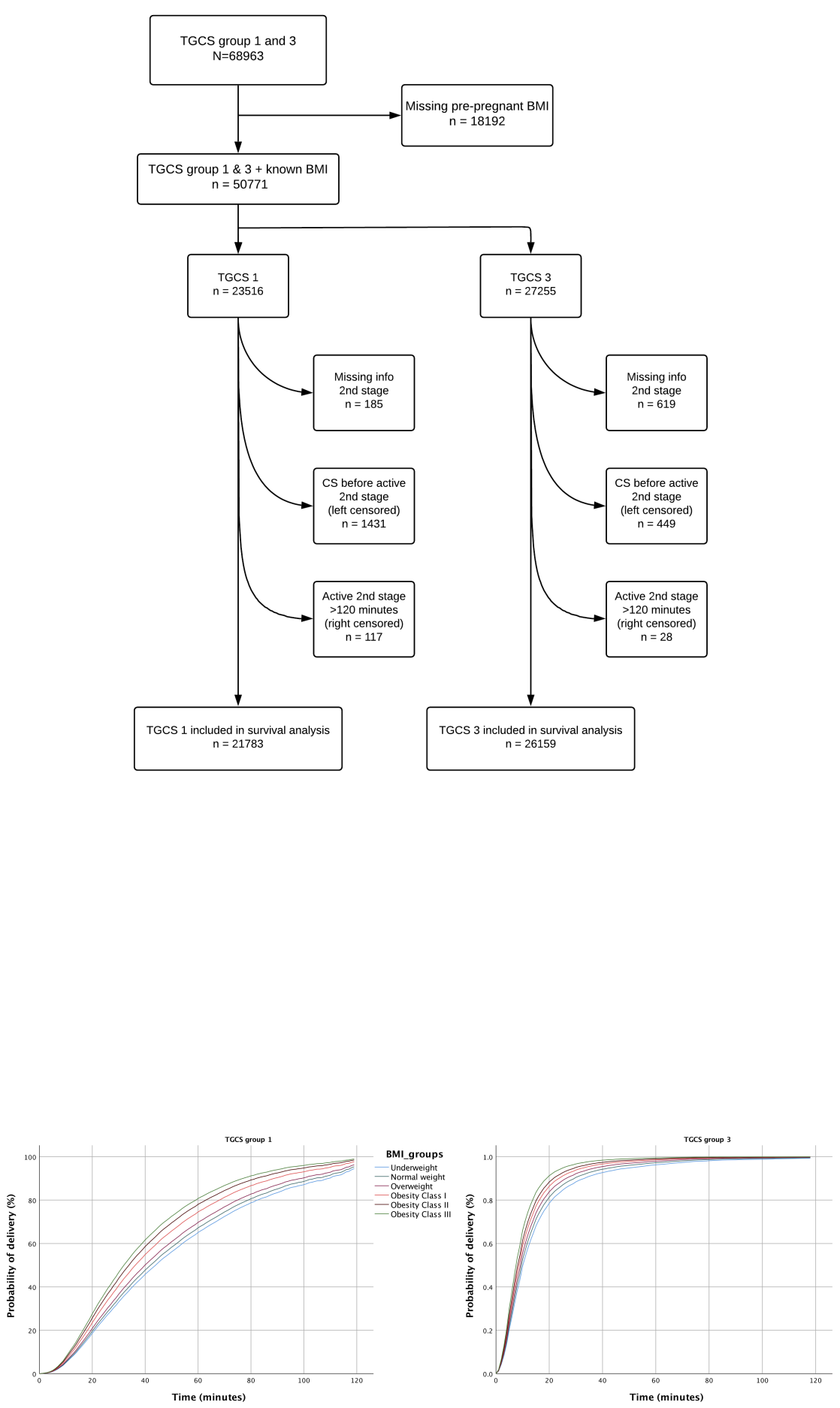


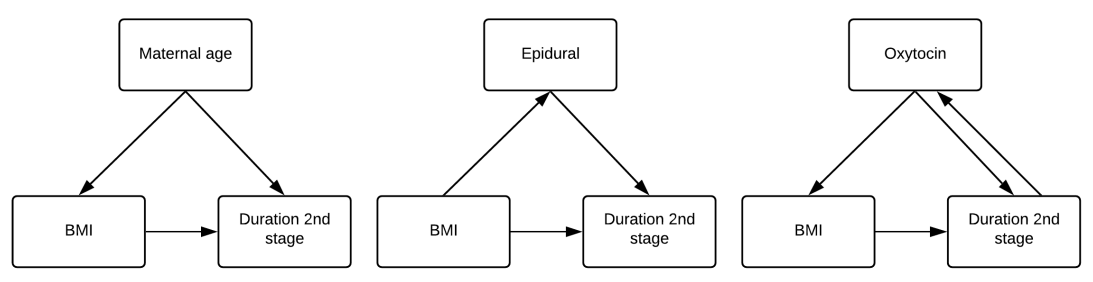

